\title{
Germination of recalcitrant Baccaurea ramiflora seeds
}

\author{
Qiang Liu ${ }^{\mathrm{a}}$, Qin Y. Lan ${ }^{\mathrm{a}, *}$, Bin Wen ${ }^{\mathrm{a}}$, Yun H. Tan ${ }^{\mathrm{a}}$, Xiao F. Wang ${ }^{\mathrm{b}}$ \\ ${ }^{a}$ Key Laboratory of Tropical Forest Ecology, Xishuangbanna Tropical Botanical Garden, \\ Chinese Academy of Sciences, Germplasm Bank, Mengla, 666303 Yunnan, China \\ b Beijing Forestry University, Beijing, 100083, China \\ *Corresponding author, e-mail: lqy@xtbg.org.cn
}

Received 18 Jul 2012

Accepted 28 Oct 2013

\begin{abstract}
Tolerance to desiccation in recalcitrant seeds depends on the genetic background and the developmental conditions of the seeds, both of which are relevant to harvest and storage for conservation purposes. The tropical south and south-east Asian species, Baccaurea ramiflora Lour., has recalcitrant seeds and is a locally important resource. We measured germination success and desiccation tolerance of $B$. ramiflora at different temperatures and light conditions for 76, 86, 96, and 106 days after anthesis to describe seed germination requirements and the relationship between seed development and desiccation tolerance of seeds for storage. We found that light is not an important factor in B. ramiflora seed germination, and that optimal seed germination conditions occur at 30/20 ${ }^{\circ} \mathrm{C}$. During their development from $76-106$ days after anthesis, seeds and their embryonic axes undergo changes in morphological characteristics, germination ability, moisture content, and desiccation tolerance. The best time for collection of B. ramiflora seeds for storage is around 96 days after anthesis, when desiccation tolerance is maximal.
\end{abstract}

KEYWORDS: Burmese grape, tropical forest tree

\section{INTRODUCTION}

Seeds are traditionally categorized as either recalcitrant or orthodox ${ }^{1}$. Orthodox seeds can be dried to low moisture content $(2-5 \%)$ and stored at low temperatures. Recalcitrant seeds have a high moisture content (often $>30-50 \%$ ) at maturity, and are sensitive to desiccation at moisture contents below $12-30 \%$, depending on the species. Recalcitrant seeds have a short storage potential and can rapidly lose viability under storage conditions ${ }^{2}$. It is believed that desiccation tolerance depends not only on the inherent characteristics of the species, but also on the developmental status of the seeds, and the environmental conditions in which they are dried, particularly the rate of dehydration ${ }^{3}$.

Baccaurea ramiflora Lour., a member of the Euphorbiaceae family, is found in the tropical forests of south and south-east Asia, and is an important tree for local people and forest ecology. The fruits of $B$. ramiflora are a food source, and the hard and durable wood is often used in furniture production ${ }^{4}$. Research on B. ramiflora has included its ethnobotanical uses, seed biology, and chemical constituents of essential oils ${ }^{5-7}$.

In tropical forests, light is one of the most important abiotic resources, and can influence the timing of seed germination ${ }^{8,9}$. B. ramiflora seeds shed in summer and like other species with recalcitrant seeds germinate quickly in the field independent of the light conditions ${ }^{10}$. Once they are shed from the parent plant, recalcitrant seeds lose viability when exposed to extreme dry or cold conditions. Unlike orthodox seeds, recalcitrant seeds cannot be stored for a long period at low temperatures. Thus it is challenging to maintain a regular supply of these seeds for genetic conservation purposes ${ }^{3,11}$. At the moment, cryopreservation is considered one of the best alternatives for long-term conservation of plant germplasm ${ }^{12}$. However, the application of exogenous $\mathrm{CO}$ or $\mathrm{NO}$ markedly improved the tolerance of B. ramiflora seeds to low-temperature stress ${ }^{13}$. Importantly, desiccation tolerance in recalcitrant seeds differs at each developmental stage ${ }^{3}$.

Suitable temperature and light, are important for seed germination. The objectives of the present study were to determine (1) the light and temperature conditions best suited for seed germination of $B$. ramiflora, and (2) the time needed for $B$. ramiflora seeds to reach physiological maturity for seed harvest collection and further study of seed storage.

\section{MATERIALS AND METHODS}

\section{Materials}

Seeds of B. ramiflora at different developmental stages were collected from trees grown in Xishuangbanna Tropical Botanical Garden of the Chinese Academy of Sciences, Yunnan, Southwest China. 
Table 1 Physical changes of $B$. ramiflora seeds and embryos during development.

\begin{tabular}{lcccc}
\hline & \multicolumn{4}{c}{ Days after anthesis (DAA) } \\
\cline { 2 - 5 } & 76 & 86 & 96 & 106 \\
\hline seed fresh weight $(\mathrm{mg})$ & $58.5 \pm 8.9$ & $63.7 \pm 1.9$ & $64.7 \pm 3.8$ & $56.6 \pm 2.8$ \\
seed dry weight $(\mathrm{mg})$ & $23.0 \pm 4.9$ & $25.53 \pm 0.80$ & $28.5 \pm 1.6$ & $23.43 \pm 0.91$ \\
fruit size $\left(\mathrm{cm}^{3}\right.$ ) & $10.20 \pm 0.09$ & $15.00 \pm 0.30$ & $17.90 \pm 0.19$ & $15.44 \pm 0.12$ \\
embryo fresh weight (mg) & $25.8 \pm 6.6$ & $30.3 \pm 1.3$ & $31.7 \pm 6.5$ & $28.7 \pm 2.0$ \\
embryo dry weight $(\mathrm{mg})$ & $8.5 \pm 2.0$ & $10.54 \pm 0.52$ & $14.0 \pm 4.9$ & $9.33 \pm 0.72$ \\
thousand seed weight $(\mathrm{g})$ & $299 \pm 17$ & $318 \pm 22$ & $330 \pm 37$ & $283 \pm 32$ \\
\hline
\end{tabular}

Values are mean \pm SEM, 5 replicates of 3 seeds and 5 replicates of 2 embryos for the fresh weight and dry weight, 10 replicated with 1 fruit for the fruit size.

Seed age was monitored by tagging at anthesis (on the day that most of the flowers on the tree had bloomed) and fruits were harvested at intervals of 10 days from 76-106 days after anthesis (DAA). The final collection day was the time at which most seeds were naturally shed from the tree.

\section{Measurement of seed weight, moisture content and fruit volume}

Seeds and their embryos collected at different developmental stages were weighed for fresh weight, then dried at $103{ }^{\circ} \mathrm{C}$ for $17 \mathrm{~h}$ and reweighed to determine dry weight and moisture content (MC) in 5 replicates of 3 seeds and 5 replicates of 5 embryos. MC was expressed in $\mathrm{g}$ per dry weight $\left(\mathrm{g} \mathrm{H}_{2} \mathrm{O} / \mathrm{g} \mathrm{DW}\right)$. A thousand seed weight was determined with 5 replicates. Fruit volume was measured by a single fruit (10 replicates) with water excluded in a $200 \mathrm{ml}$ volumetric cylinder.

\section{Germination requirement test}

Four replicates, each of twenty seeds were sown on moist filter paper in closed Petri dishes and placed in an incubator with $14 \mathrm{~h}$ light and $10 \mathrm{~h}$ darkness with temperatures of $15^{\circ} \mathrm{C}, 20^{\circ} \mathrm{C}, 25^{\circ} \mathrm{C}, 30^{\circ} \mathrm{C}$, and $20 / 30^{\circ} \mathrm{C}$ (light/darkness). The number of seeds germinated was recorded every 2 days over 30 days. The seeds were considered as germinated when the radicle length was larger than $2 \mathrm{~mm}^{14}$.

\section{Desiccation treatment}

Seeds from each developmental stage were desiccated in a closed glass container $(26 \mathrm{~cm}$ in diameter and $17 \mathrm{~cm}$ in height) over activated silica gel at $25^{\circ} \mathrm{C}$ for $1 \mathrm{~h}, 2 \mathrm{~h}, 4 \mathrm{~h}, 6 \mathrm{~h}, 8 \mathrm{~h}$, and $12 \mathrm{~h}$. The ratio of silica gel to seed was $15: 1(\mathrm{v} / \mathrm{v})$ and silica gel was regenerated every $24 \mathrm{~h}$. Germination tests were performed in darkness at $25^{\circ} \mathrm{C}$ by sowing 4 replicates of 15 seeds or
10 embryos on moist filter paper in closed Petri dishes in an incubator for 30 days.

\section{RESULTS}

\section{Physical changes in seeds and embryos during development}

Changes in fresh weight, dry weight, moisture content, and size of B. ramiflora seeds and fruits throughout their development are shown in Table 1. The fresh and dry weights of seeds and excised embryos exhibited similar changes: a gradual increase during the early stage of development, reaching a maximum at 96 DAA, followed by a slight decrease. From 7696 DAA, fruits grew from $10.2 \mathrm{~cm}^{3}$ to a maximum of $17.9 \mathrm{~cm}^{3}$ in volume. Development of $B$. ramiflora seeds was completed at 106 DAA, when the seeds were naturally shed (Table 1). The moisture content of seeds was high (above $1.73 \mathrm{~g} \mathrm{H}_{2} \mathrm{O} / \mathrm{g} \mathrm{DW}$ ) prior to 76 DAA, then decreased to the minimum at 96 DAA (1.27 $\mathrm{g} \mathrm{H}_{2} \mathrm{O} / \mathrm{g} \mathrm{DW}$ ), and increased by the final collection. Embryo maximum moisture content occurred at 86 DAA (2.14 $\left.\mathrm{g} \mathrm{H}_{2} \mathrm{O} / \mathrm{g} \mathrm{DW}\right)$ and decreased to $1.84 \mathrm{~g} \mathrm{H}_{2} \mathrm{O} / \mathrm{g} \mathrm{DW}$ by $96 \mathrm{DAA}$, but increased to $2.10 \mathrm{~g} \mathrm{H}_{2} \mathrm{O} / \mathrm{g} \mathrm{DW}$ by 106 DAA (Fig. 1).

\section{Effects of light and temperature on seed germination}

Very few of the seeds incubated at $15^{\circ} \mathrm{C}$ in the light for 30 days germinated (only 1\%), and the best germination rate was at $25^{\circ} \mathrm{C}$ and $30 / 20{ }^{\circ} \mathrm{C}$. Temperature $(F=26.48, p<0.01)$ and temperature-illumination interaction $(F=4.00, p<0.05)$ had significant influence on seed germination (Fig. 2); but illumination alone was not significant $(F=0.04, p>0.05)$. There were significant differences in the proportion of germinated seeds between different temperatures, except between $25^{\circ} \mathrm{C}$ and $30 / 20^{\circ} \mathrm{C}$. The germination rate at $30 / 20^{\circ} \mathrm{C}$ was slightly better than at $25^{\circ} \mathrm{C}$, although not statistically significant $(t=0.13$, 


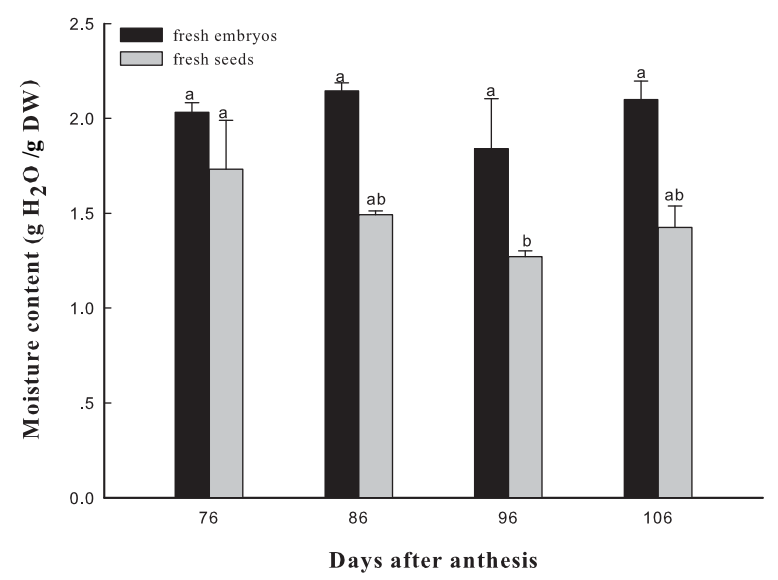

Fig. 1 Changes in moisture contents of fresh B. ramiflora seeds and embryos during development. Error bars indicate mean \pm SE, 5 replicates of 3 seeds and 5 replicates of 5 embryos. The same letters indicate that there are no significant differences between data; different letters indicate a statistically significant difference (ANOVA, $p<0.05$ ).

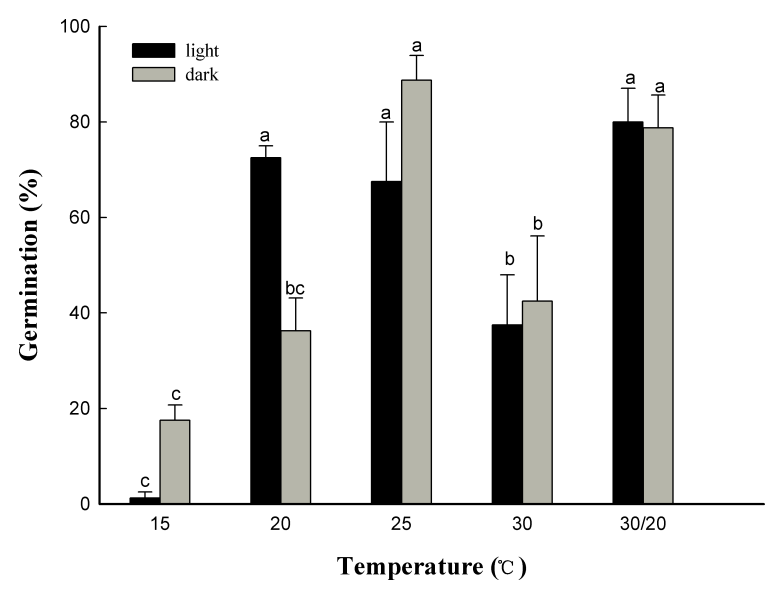

Fig. 2 Effects of light and temperature on seed germination of $B$. ramiflora. Error bars indicate mean \pm SE. Each data point is the mean of 4 replicates of 20 seeds. The same letters indicate that there are no significant differences between data; different letters indicate a statistically significant difference (ANOVA, $p<0.05$ ).

$p>0.05)$. Light had no significant effect on seed germination $(t=0.10, p>0.05)$. These results suggested that the optimum condition for germination of B. ramiflora was at $30 / 20^{\circ} \mathrm{C}$ in either dark or light condition (Fig. 2).

\section{Changes in germinability}

Germination capability of $B$. ramiflora seeds depended on their developmental stage. During early

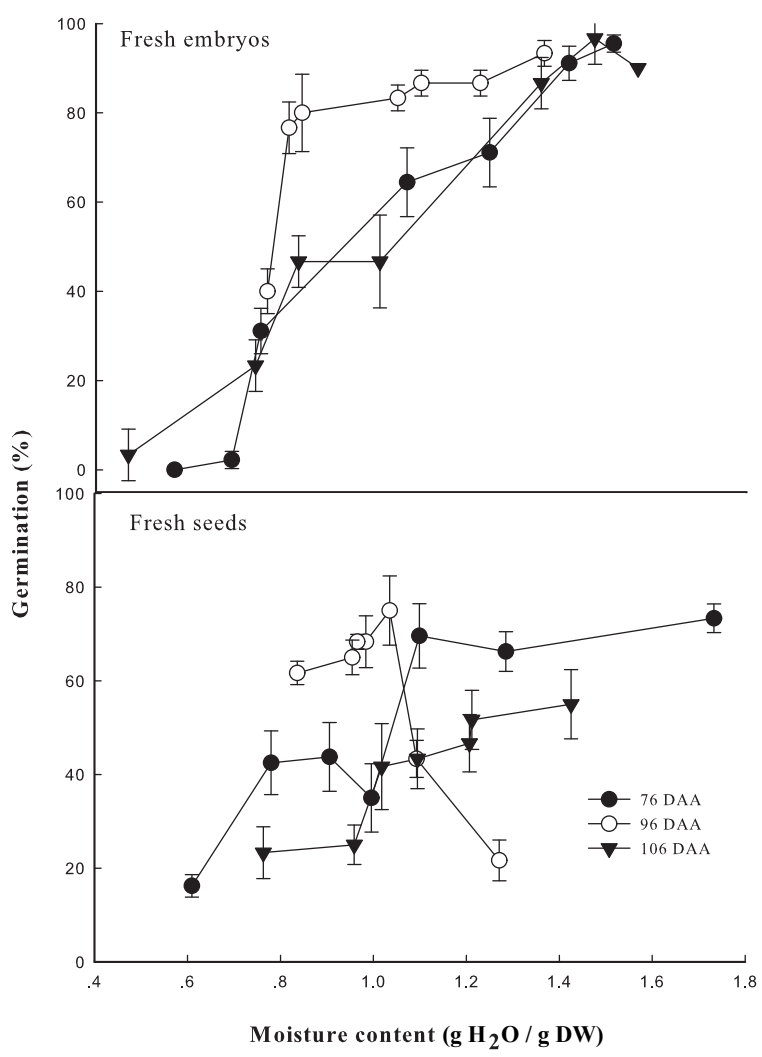

Fig. 3 Changes in germination percentage of B. ramiflora seeds and embryos during development following rapid dehydration to different moisture contents. Error bars indicate mean \pm SE, 4 replicates of 15 seeds and 3 replicates of 10 embryos.

development (before 76 DAA), seeds did not germinate, but $73 \%$ of intact seeds germinated at 76 DAA. The number of germinated seeds decreased sharply at 86 DAA (27\%), then decreased to the minimum at 96 DAA (22\%), and increased again at 106 DAA $(55 \%)$. Removal of the testa significantly increased the number of germinated seeds $(t=5.21, p<0.01)$. For example, the germination percentage of 76 DAA embryos reached $96 \%$ (Fig. 3). The one-way ANOVA showed that the changes in germination percentage for seeds during development were significant $(F=7.62$, $p<0.01)$, while that for embryos were not $(F=1.46$, $p>0.05)$.

\section{Desiccation tolerance}

Moisture content of intact seeds and embryos were highest at 76 DAA and 86 DAA, respectively, (Fig. 1) and dehydration rates were most rapid at 76 DAA for both intact seeds and embryos. After $12 \mathrm{~h}$ of rapid drying, the moisture content of seeds and 


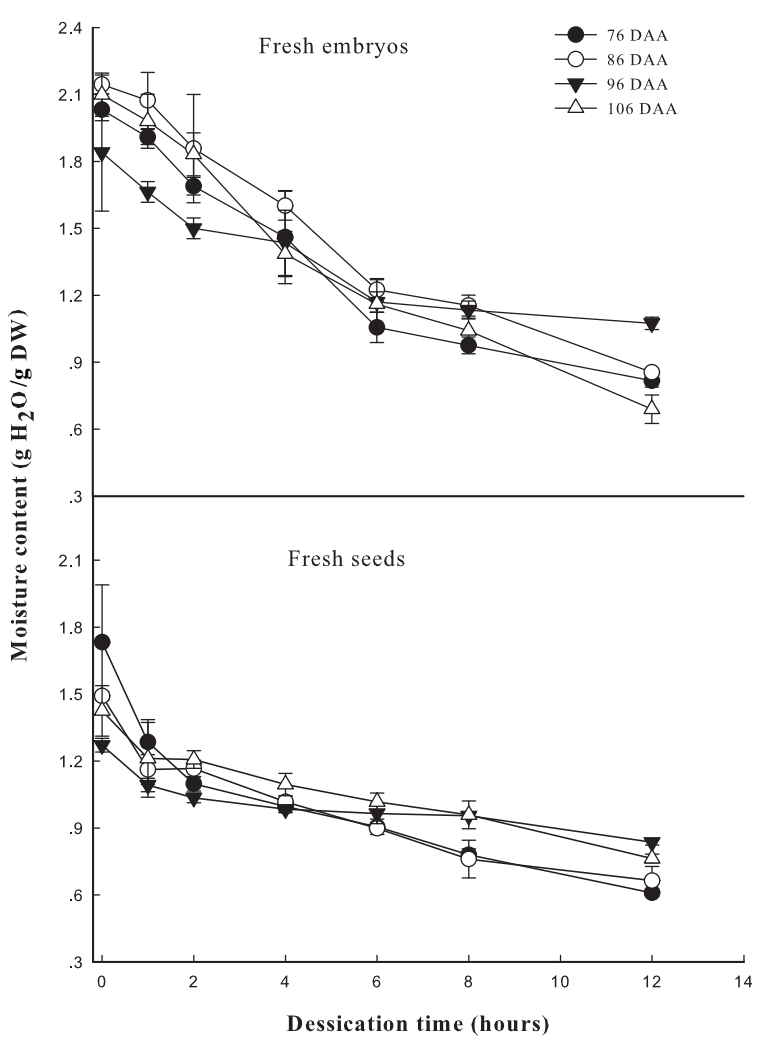

Fig. 4 Changes in moisture contents of B. ramiflora seeds and embryos during development following rapid dehydration. Error bars indicate mean \pm SE, 5 replicates of 3 seeds and 5 replicates of 5 embryos.

embryos at 76 DAA declined to minimum values of about $0.61 \mathrm{~g} \mathrm{H}_{2} \mathrm{O} / \mathrm{g} \mathrm{DW}$ and $0.82 \mathrm{~g} \mathrm{H}_{2} \mathrm{O} / \mathrm{g} \mathrm{DW}$, respectively. During development, the desiccation tolerance of seeds and their embryos increased significantly $\left(F_{\text {seed }}=4.86, p<0.05\right.$ and $F_{\text {embryo }}=4.26$, $p<0.05)$ and were greatest at 96 DAA. After that time, both seeds and embryos exhibited similar reductions in desiccation tolerance (Fig. 4). However, significant differences in seed desiccation tolerance only occurred at between 76 DAA and 96 DAA $(p=0.002), 76 \mathrm{DAA}$ and $106 \mathrm{DAA}(p=0.025)$; but for embryos, the greatest tolerance to desiccation was at 96 DAA, and was significantly different from that at 76 DAA $(p=0.034), 86$ DAA $(p=0.014)$, and 106 DAA ( $p=0.004)$. For example, after $12 \mathrm{~h}$ of rapid drying, the germination percentage of embryos dropped to $0 \%$ at $76 \mathrm{DAA}$ and $106 \mathrm{DAA}$, but $40 \%$ germination percentage remained at 96 DAA. The germination percentage of seeds had the same tendency, but the descend range was smaller than embryos' because of testa (Fig. 3).

\section{DISCUSSION}

A previous study also showed no significant difference in $B$. ramiflora seed germination between light and dark conditions in the field ${ }^{10}$. Under our laboratory conditions, the seeds of $B$. ramiflora germinated at temperatures between $20^{\circ} \mathrm{C}$ and $30^{\circ} \mathrm{C}$. The optimal germination condition was at a $30 / 20^{\circ} \mathrm{C}$ (light/ darkness) cycle in either light or darkness, which reflects its natural growing environment. In its natural habitat in the tropical rain forests of Xishuangbanna, $B$. ramiflora seeds usually germinate immediately after shedding from the trees in July when day and night temperatures average around $31^{\circ} \mathrm{C}$ and $23^{\circ} \mathrm{C}$, respectively.

Physiological maturity denotes the stage of development when a seed reaches its maximum dry weight and marks the end of the seed-filling period ${ }^{15}$. B. ramiflora seeds appear to reach physiological maturity at 96 DAA, when both seeds and embryos attained their maximum fresh weights of $64.7 \pm 3.8 \mathrm{mg}$, $31.7 \pm 6.5 \mathrm{mg}$ and dry weights of $28.5 \pm 1.6 \mathrm{mg}$, $14.0 \pm 4.9 \mathrm{mg}$, respectively. In other studies, germination ability increased with seed development ${ }^{16-18}$, but in this study most seeds germinated at 76 DAA, and germination rate decreased with further development with fewest seeds germinating at 96 DAA (22\%), but the excised embryo reached $93 \%$ (Fig. 3), and we observed the same pattern at other stages. Apparently, the tissues enclosing the embryonic axis, such as pericarp, cotyledon, and testa, may inhibit growth elongation along the embryonic axis under conditions conducive to germination, which may have an important role in preventing viviparous germination $^{18}$. Alternatively, the testa of $B$. ramiflora would prevent moisture loss in seeds and maintain longer viability, especially in the case of continuous high temperature. Rapid dehydration treatment can weaken this inhibitory effect on germination along with seed development, and the most significant stage was at 96 DAA.

In summary, like $\mathrm{Yu}$ et $\mathrm{al}^{10}$, we found that temperature but not light is an important factor for $B$. ramiflora seed germination, and seeds almost could not germinate below $20^{\circ} \mathrm{C}$. Optimal seed germination occurs at $30 / 20^{\circ} \mathrm{C}$ in either light or darkness. Desiccation tolerance depends not only on the inherent characteristics of the species, but also on the developmental status of the seeds, which is the key factor for long-term storage of recalcitrant seeds. Based on our results, the best time for collection of $B$. ramiflora seeds for storage is around 96 DAA when desiccation tolerance is maximal. 
Acknowledgements: We thank Prof. Carol C. Baskin for careful editing of the English, and giving valuable comments on the manuscript. This work was supported by the China National Forest Department 948 Project (Grant no. 2011-454), the Knowledge Innovation Project of Chinese Academy of Sciences (KSCXZ-SW-117), the Supporting System Program of Strategic Biological Resources of the Chinese Academy of Sciences (08ZK121B01) and the Ministry of Science and Technology of China (2005DKA21006).

\section{REFERENCES}

1. Roberts EH (1973) Predicting the storage life of seed. Seed Sci Tech 1, 499-514.

2. King MW, Roberts EH (1979) The Storage of Recalcitrant Seeds: Achievements and Possible Approaches, International Board for Plant Genetic Resources, Rome.

3. Pammenter NW, Berjak P (1999) A review of recalcitrant seed physiology in relation to desiccationtolerance mechanisms. Seed Sci Res 9, 13-37.

4. Li BT (1999) Flora of China, Vol. 44. Science Press, Beijing, pp 131-2.

5. Chen J, Su YC, Chen GQ, Wang WD (1999) Ethnobotanical studies on wild edible fruit in Southern Yunnan: folk names; nutritional value and uses. Econ Bot 53, 2-14.

6. Normah MN, Saraswathy DR, Gintangga M (1997) Desiccation sensitivity of recalcitrant seeds-a study on tropical fruit species. Seed Sci Res 7, 179-84.

7. Yang XW, Wang JS, Ma YL, Xiao HT, Zuo YQ, Lin H, He HP, Li L, Hao XJ (2007) Bioactive phenols from the leaves of Baccaurea ramiflora. Planta Med 73, 1415-7.

8. Swaine MD, Whitmore TC (1998) On the definition of ecological species groups in tropical rain forests. Vegetatio 75, 81-6.

9. Vásquez-Yanes C, Orozco-Segovia A (1994) Signals for seeds to sense and respond to gaps. In: Caldwell MM, Pearcy RW (eds) Exploitation of Environmental Heterogeneity by Plants: Ecophysiological Processes Above- and Below-ground. Academic Press, San Diego, pp 209-36.

10. Yu Y, Baskin JM, Baskin CC, Tang Y, Cao M (2008) Ecology of seed germination of eight non-pioneer tree species from a tropical seasonal rain forest in southwest China. Plant Ecol 197, 1-16.

11. Hoekstra FA, Golovina EA, Buitink J (2001) Mechanisms of plant desiccation tolerance. Trends Plant Sci 6, 431-8.

12. Ashmore SE (1997) Status Report on the Development and Application of in vitro Conservation and Use of Plant Genetic Resources. IPGRI, Rome.

13. Bai XG, Chen JH, Kong XX, Todd CD, Yang YP, Hu XY, Li DZ (2012) Carbon monoxide enhances the chilling tolerance of recalcitrant Baccaurea ramiflora seeds via nitric oxide-mediated glutathione homeostasis. Free Radic Biol Med 53, 710-20.
14. International Seed Testing Association (1999) International rules for seed testing. Seed Sci Tech 27, 1-333.

15. Shaw RH, Loomis WE (1950) Bases for the prediction of corn yields. Plant Physiol 25, 225-44.

16. Luo YL, Song SQ, He HY, Lan QY (2005) Changes in desiccation tolerance of maize embryos during its development. Acta Bot Yunnan 27, 301-9.

17. Shao YT, Yin SH, Lan QY, Zhang XY (2006) Developmental changes in relation to desiccation tolerance of Archontophoenix alexandrae (Palmae) seeds. Acta Bot Yunnan 28, 515-22.

18. Lan QY, Jiang XC, Song SQ, Lei YB, Yin SH (2007) Changes in germinability and desiccation-sensitivity of recalcitrant Hopea hainanensis Merr. et Chun seeds during development. Seed Sci Tech 35, 21-31. 